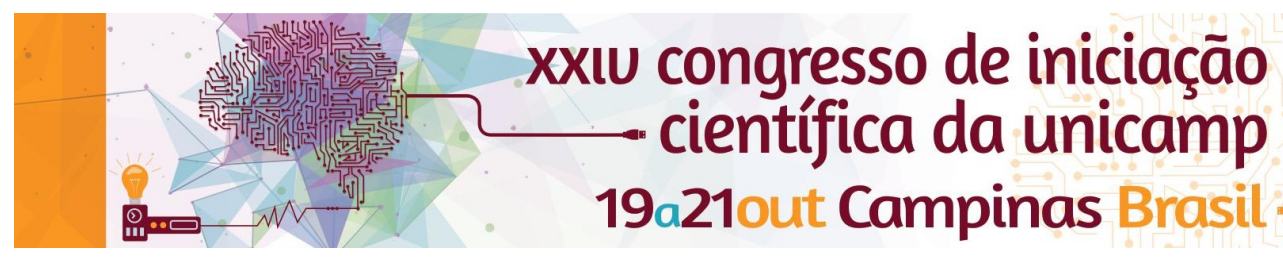

\title{
Limiares de detectabilidade em mamografia digital
}

\author{
Mariana Yuamoto*, Alessandra Tomal.
}

\section{Resumo}

Um grande desafio nos exames mamográficos é produzir uma imagem de alta qualidade para permitir a visualização de alterações com menores dimensões, e garantir um diagnóstico precoce. O estudo quantitativo desse problema baseiase na determinação do contraste da imagem e razão contraste-ruído. Através da avaliação qualitativa e quantitativa da qualidade da imagem, foram definidos limiares de detectabilidade para objetos simuladores que incluem diversos detalhes contrastantes.

\section{Palavras-chave:}

Imagem mamográfica, contraste, CNR (razão contraste-ruído).

\section{Introdução}

O câncer de mama é o maior responsável por óbitos em mulheres. A mamografia é a técnica mais utilizada para o diagnóstico precoce, que é a forma mais eficaz de reduzir a mortalidade. Uma imagem de alta qualidade é essencial para possibilitar a detecção de alterações de pequenas dimensões e baixo contraste [1-4]. O objetivo deste trabalho é estudar essas grandezas que quantificam a qualidade da imagem para diferentes parâmetros de exposição (produto corrente-tempo - mAs, combinação alvo-filto (potencial do tubo - $k V p$ ), comparando com os limiares de detectabilidade obtidos através da análise subjetiva.

\section{Resultados e Discussão}

As imagens de objetos simuladores de mama (CIRS, Inc. Norfolk, VA) foram adquiridas em um mamógrafo Hologic Dimensions, instalado no Instituto de Radiologia (INRADHCFM USP).

As imagens foram avaliadas quantitativamente através da determinação do contraste e da razão sinal ruído [1-2] para diferentes estruturas dentro do simulador. Posteriormente, os limiares de detectabilidade para massas tumorais foram definidos subjetivamente classificando-as como visível ou invisível. O trabalho se desenvolveu na análise de limiares de detectabilidade em função da variação do $\mathrm{kV}, \mathrm{mAs}$, alvo e filtro.

Para análise dos resultados, as massas esferícas foram nomeadas de 1 a 7 , tendo as respectivas dimensões de $0,9 \mathrm{~mm}$ a $4,76 \mathrm{~mm}$.

Para a obtenção dos resultados, foram adquiridas imagens para as combinações alvo/filtro (W/Rh e W/Ag) para diferentes $\mathrm{kVp}$. Para cada imagem obtida em função do $\mathrm{KVp}$, foram determinados os valores contraste e CNR relacionados aos limiares de detectabilidade.

A Figura 1 exemplifica a análise dos limiares do contraste em função dos limiares do CNR para as últimas massas esféricas visíveis. A figura representa dados de uma imagem for processing (sem processamento) e contém características de dois tipos de filtro (ródio e prata) disponíveis no equipamento. Observa-se uma relação linear entre contraste e CNR, onde o coeficiente angular representa o ruído relativo que é constante para que as estruturas sejam visíveis.

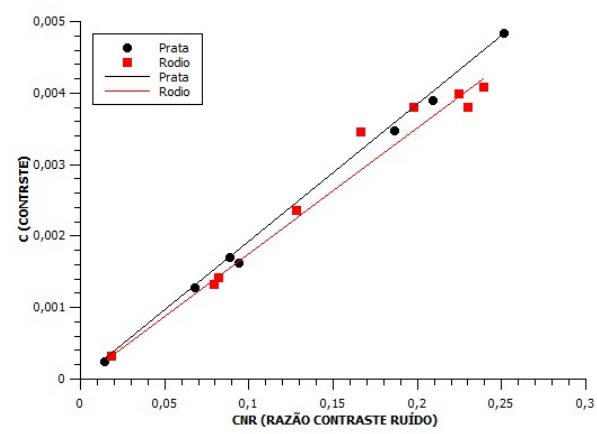

Figura 1. Limiares do contraste em função dos limiares do CNR para as últimas massas esféricas visíveis.

\section{Conclusões}

Verificamos que para uma espessura de $43 \mathrm{~mm}$ os valores de $\mathrm{mAs}$ mais prováveis de visualização ficaram em torno de 49,6-159,1 enquanto que para a espessura $60 \mathrm{~mm}$ esse valor variou entre 19,9-99,7. Observou-se também que as melhores condições de visualização foram obtidas nos intervalos de diferenças de potencial $24-32 \mathrm{kV}$ e $24-37 \mathrm{kV}$ para os filtros de ródio e prata, respectivamente.

Além disso, verificamos a dependência linear entre o contraste e o CNR, o que implica em um ruído constante como apresentado na Figura 1. Obtivemos um ruído de 0,018 para o filtro de ródio e 0,0189 para a prata, e assim, verificamos a não dependência com o filtro.

Podemos concluir que esse tipo de estudo é importante para a otimização das condições de realização do exame.

\section{Agradecimentos}

Os autores agradecem ao CNPQ (Processo 483170/20135) e a Fapesp (Processo 2015/07267-8) pelo auxílio financeiro concedido.

1. D. M. Cunha, et al,. Physics in Medicine and Biology, 2012, vol. 57, pp 1919-1935.

2. P. Toroi, et al., Eur. Radiol., 2007, vol. 17, pp. 2368-2375.

3. A. Tomal, et al., IEEE Transactions on Nuclear Science, 2013, vol. 60, pp 728-734.

4. W. Huda, et al., Med. Phys., 2003, vol. 30, pp. 442-8. 